Review

\title{
INFLUENCING FACTORS LEADING TO DAMAGING BEHAVIOR - FEATHER PECKING AND CANNIBALISM IN GAME BIRDS
}

\author{
S. Nikolov*, D. Kanakov \\ Department Internal Non-infectious Diseases, Faculty of Veterinary Medicine, Trakia University, \\ Stara Zagora, Bulgaria
}

\begin{abstract}
Behavioural disorders, including feather pecking and cannibalism, are a common problem in both domestic and wild birds. Damaging behaviour is polyethiological and is divided into two major groups of factors: extrinsic and intrinsic. Extrinsic factors are those that are not dependent on the species of bird-factors from outside the organism which causes injurious pecking (IP). There are three abiotic groups assigned: nutritional factors (the composition of the ration and nutritional strategies), factors of the environment (light, temperature, sound, and air), and conditions of breeding (density, size, type of system, and enrichment of the conditions of breeding). Intrinsic are the factors that depend on the species of bird - factors coming from the organism and influencing injurious pecking. Seven biotic factors are assigned: social (imitating, sexual, stereotypical and maternal behaviour), sex (male and female sex hormones), age (young and adult), stress (fear, stress and corticosterone), central-nervous (serotonin, dopamine and noradrenaline), hereditary (genotypic and phenotypic manifestation) and immunological. It is important to have an understanding of the influencing factors leading to an onset of injurious pecking in order to successfully control the behavior in game birds bred in captivity.
\end{abstract}

Key words: damaging behavior, injurious pecking (IP); feather pecking (FP); cannibalism, pheasant, game birds

\section{INTRODUCTION}

The main obstacle when breeding game birds in captivity or a large number of domestic birds in one area is the onset of injurious pecking (IP) which leads to a decline in their welfare $(1,2)$. This results in serious economic losses in many European game farms that breed wild birds in captivity (in an aviary for release/displacement and shooting). (3, 4) The relevance of the problem is also associated with the increased number of wild birds bred commercially for game meat production (5-7). Despite the extensive research in the field, this bird welfare problem is still relevant as far as the humane treatment of the birds goes $(2,8)$. The goal of this review is to provide a

\footnotetext{
*Correspondence to: Slavko Nikolov, Department of Internal Non-infectious Diseases, Faculty of Veterinary Medicine; Trakia University, Students' Campus 6015 Stara Zagora, Bulgaria, GSM: +359897880597, e-mail: slavko92@outlook.com
}

detailed classification of the influencing factors leading to damaging behavior in game birds. The abiotic and biotic factors are reviewed as well as the interaction between the environment and the organism, leading to stressful situations and dissatisfaction in the birds which unlocks deviations in their behavior.

The etiology of feather pecking and cannibalism is multifactorial with two main groups of factors being involved: extrinsic and intrinsic (9-11).

I.Extrinsic factors. External factors are those that don't depend on the species of bird factors outside of the organism that causes injurious pecking. There are three abiotic groups assigned: nutritional factors, factors of the environment (light, temperature, sound, and air), and conditions of breeding (spatial 
parameters, type of system and enrichment of the conditions of breeding).

1.Nutritional factors: These factors play a key role in the potential development of feather pecking (FP) as the specific way of feeding is strongly connected with cannibalism in birds $(12,13)$.

1.1 Composition of the ration: It is known that the composition of the ration influences damaging behavior in birds (14-16). The nutritional deficit stimulates injurious pecking in game birds $(5,6)$, in the exploitation of domestic birds it can increase feather pecking and cannibalism (1). The amount of protein, minerals, energy values, and fibers can influence heavy feather pecking (8).

1.1.1 Content of proteins and amino acids. The nutritional deficit of raw protein and essential amino acids leads to an increase in damaging behavior in birds which results in poor condition of the feathers and higher mortality caused by cannibalism $(13,17)$.

- Raw protein: Diets with low content of proteins are connected to an increase in feather pecking and higher mortality rates attributed to cannibalism $(13,18)$. Diets with an increased content of proteins (casein, gelatine, liver flour, blood flour, soy oil flour, cotton seed, and others) have a positive effect on the feathering and lower injurious pecking (12, 17).

- Amino acids: The sulfur-containing amino acids such as methionine and cysteine have an important role in the development of the feathers (18) which is connected to the frequency of injurious pecking (19). Ruffled or inappropriately grown feathers (abnormal feathering) encourage the behavior of feather pecking and even cannibalism (17). More important is the role of the aromatic amino acids: tryptophan (TRP), phenylalanine (PHE) and tyrosine (TYR) which are precursors for the synthesis of monoamine neurotransmitters (serotonin and dopamine) and catecholamines (noradrenaline) which are responsible for the regulation of injurious pecking in birds (10) reviewed in factors of CNS. Additional placement of the amino acids lysine (17) and arginine (20) also supports the improvement of feathering and lowers the levels of feather pecking and cannibalism in pheasants and gray partridges $(21,22)$.

- Value of origin of the protein source: The replacement of animal protein with one of plant origin increases the frequency of feather pecking and cannibalism. $(12,17)$. Additional
NIKOLOV S., et al.

placement of proteins from animal sources (fish flour, meat, and bone flour or sources of milk proteins, vit. B12) lowers the onset of injurious pecking (23). Meanwhile, the content of plant proteins in the ration has a negative effect on birds since they contain phytoestrogens which increase the plasma concentrations of estradiol and cause the behavior of feather pecking and cannibalism (23).

1.1.2 Content of minerals: High levels of magnesium in the bird ration lower injurious pecking tendencies (1). Severe feather pecking has an increase in cases of nutritional deficit of magnesium in the ration (17). The element zinc has a positive influence on the feathering and the levels of injurious pecking in birds $(1,20$, 24). The addition of zinc to the ration when there is a deficit significantly improves the condition of the feathering $(15,25)$. The content of sodium in the diet influences the condition of the feathering and increases the activity of the birds as well as injurious pecking (1). It is proven that high levels of selenium are the reason for aggression and higher mortality from cannibalism between adult pheasants as well as a higher mortality rate in embryos (26).

1.1.3 Content of fibers and roughages: The addition of fibers to the diet or feeding roughages can significantly lower injurious pecking in birds $(27,28)$. When there's a lack or insufficiency of non-starch polysaccharides (NSP) the birds acquire them through eating feathers (29), meaning the levels of feather picking and cannibalism increase (1). A number of studies confirm that the high content of NSP in the ratio of birds is useful for the prevention of injurious pecking (13). Providing roughages (green clover and beech leaves) in pheasants (30) or grass, beets, carrots in chickens lowers injurious pecking (31).

1.1.4 Energy content: The energy content in the ration can also influence injurious pecking (13). The increase of energy content in the ration increases the reception of energy and leads to higher mortality from cannibalism and a significant worsening of the feathering (18). Rations with low energy content increase the consuming behavior and the amount of consumed forage which lowers the possibility of feather pecking development or cannibalism (14). 


\subsection{Nutritional strategies:}

1.2.1 Changes in the ration: It is known that birds are very sensitive towards sudden changes in their ration $(11,32)$. Changes in the ration increase injurious pecking $(28,33)$ and vent pecking (34).

1.2.2 Physical form of the forage and size of the pieces: The physical form of the forage being fed (mash, crumbs, or pellets) and the distribution of particles in the ration of the birds can influence the behavior of feather pecking due to changes in the time needed to consume the forage $(11,31)$. Feeding with dust form forages such as mash lowers injurious pecking while feeding with granulated forage increases the frequency of damaging behavior $(9,14)$.

2. Factors of the environment: The interaction between the abiotic factors such as light, temperature, sound and air quality can significantly influence the development of damaging behavior $(15,35)$. Factors of the environment can create stressful situations for the birds because they are much more sensitive than humans to changes in the environment $(16,36)$. That way birds try to overcome the unfortunate conditions and they resort to injurious pecking as a way of coping $(11,37)$.

2.1 Light factor: Contrary to humans that have trichromacy vision birds have tetrachromatic color vision and are capable of perceiving the UV part of the light spectrum $(9,36)$. Birds are highly sensitive to light and its parameters: light intensity, duration of the photoperiod, and wavelength. They can influence injurious pecking $(38,39)$.

2.1.1 Intensity of light: Overexposure to light/ the higher light intensity increases the feather pecking behavior and cannibalism in birds (9, 35). On thecontrary low intensity of light lowers injurious pecking $(16,36)$.

2.1.2 Photoperiod: Breeding in conditions of permanent (24 hour) light day of newly hatched chickens significantly increases injurious pecking in adult age $(8,40)$. The normal photoperiod which can be achieved by the use of dark brooder significantly decreases injurious pecking in birds. Those way active chickens can be divided from inactive chickens (36).

2.1.3 Wavelength: The specific wavelength in the color spectrum - red and blue light (11) as well as UV light influences the behavior of feather pecking and cannibalism $(38,39)$. They change the perception of the birds towards colors, details and reflective capabilities of the
NIKOLOV S., et al.

feathering (41) and they also influence the activity of injurious pecking (35).

2.2 Temperature factor: Providing an appropriate zone of thermal comfort is an important component of the welfare of birds and lowers the behavior of feather pecking (11, 16). Low as well as high temperatures lead to thermal stress and the birds develop injurious pecking $(32,37)$.

2.3 Sound factor: The connection between sound and stress in birds $(11,37)$ has been proven in means of different waves of sound leading to various behavioral reactions on their behalf (35). Strong mechanical noise leads to negative effects in birds; causes stress and in after effect the development of injurious pecking $(9,36)$.

2.4 Air factor: Good ventilation and quality of air in the breeding areas are significant for the welfare of the birds $(8,42)$. Poor ventilation of air leads to a buildup of harmful gases. When there is an increase in the concentration of carbon dioxide (16), hydrogen sulphide, or ammonia the damaging behavior increases (35, 39). Mechanical pollution and dusting in the air of breeding areas are also a factor leading to injurious pecking $(37,42)$.

3. Factors of breeding conditions/ homing climate: The homing climate is of great importance for the development of feather pecking and cannibalism in birds. It depends on the parameters of the area and the division between the birds, the type of breeding system and environment enrichment (available bedding, perch stands, types of drinkers and feeders and aerated breeze blocks $(13,38,39)$.

3.1 Spatial parameters and division of the birds: The characteristics of the limited areas such as density of breeding and size of the group can significantly change the way birds cooperate between each other and how they use the resources they've been given $(16,43)$ which includes the free space and size of the confinement (44).

3.1.1 Density of breeding: The density of breeding is the main factor that influences injurious pecking in game birds $(5,6,30)$. The higher density of breeding increases injurious pecking. $(9,32)$

3.1.2 Size of the group: The size of the group has a significant influence on cannibalism in pheasants $(4,30)$. Feather pecking and forms of cannibalistic behavior are most commonly seen in birds bred in large groups $(10,13)$. The smaller size of the group and usage of conventional and furnished cages are 
NIKOLOV S., et al.

connected to lower levels of injurious pecking compared to the big sized bird groups typical for free systems of breeding - look at the types of breeding systems $(43,45)$.

3.1.3 Usage of free space: The bigger access to a free area or a prolonged period on the outside severely reduces injurious pecking in birds $(44,46)$.

3.1.4 Influence between spatial parameters: The three factors are in correlation since density is a direct consequence of change in the size of the group or the size of the confinement which makes it harder to determine the individual influence of every factor leading to injurious pecking on its own $(36,44)$. The bigger number of birds limits the possibility of movement and spreading of the individuals (32) which contributes to the usage of less free space while in small groups it is the opposite (46). Breeding of birds in high density with little space and a big number of birds increases the possibility of birds interacting with each other (11). The small confinements with low density and a small number of birds use the area and activity in the most balanced way which lowers feather pecking and cannibalism most effectively (44).

3.2 Type of breeding system: A base for good welfare of the birds is to have them placed in conditions that are specific for each individual species, as close as possible to their natural habitat $(7,47)$. Breeding of birds in closed spaces (cage or no cage), outside (aviary cages with a yard) or in bio farms and the way they are managed directly interferes with the development of damaging behavior $(32,38$, 40).

3.2.1 Systems of free breeding in a closed confinement: Feather pecking is seen in all systems of bird breeding $(12,36)$ but is a main problem in free living systems $(43,48)$ where the pecking birds have access to a large number of potential victims and the culprits can't be easily identified (45).

3.2.2 Systems of free breeding outside: Breeding outside and the duration of time in the sun (33) can influence the onset of injurious pecking $(36,39)$. The placement of natural or superficial covers over the bird aviary in birds bred outside lowers the onset of feather pecking (46).

3.2.3 Systems of conventional cage breeding: In cage breeding where the size of the group is smaller the order of hierarchy is more stable and problems with feather pecking develop less $(45,49)$. In domestic birds bred in a conventional cage system with higher density we observe a decrease in productivity and higher mortality: feather pecking, cannibalism and an increase in the manifestation of fear (47). That stands as well for pheasants bred in conventional cages which show behavioral disturbances: aggression, cannibalism and higher mortality $(7,50)$.

3.3 Enrichment of the environment: An alternative way to prevent damaging behavior in birds is the enrichment of the environment $(11,12)$.

3.3.1 Influence of the feeders and drinkers: The type of feeding device and the way food is provided highly influences the bird's behavior (27). Birds that have access to operating, hanging or segmented mechanical feeders develop a high sense of competitiveness and disappointment in the feeding which leads to injurious pecking (16). Using a mixed type feeder lowers the feeding competitiveness and damaging behavior (36). Satisfying the water needs and hydration of the birds is an important moment because it can onset injurious pecking (11). Usage of drinkers from the bell type increases feather pecking $(34,43)$. Nipel drinkers decrease injurious pecking in birds (9).

3.3.2 Availability of bedding/ nutritional substrate: Ensuring that there is a substrate with a good quality is important for the welfare of birds and makes the job of the bird breeders easier $(11,51)$. It is widely acclaimed that the feathering is in better condition when there is bedding available because it allows the normal behavior of digging and bathing in it $(8,16)$. Making bedding available in young age significantly decreases injurious pecking in adult age $(9,17)$. An increase in injurious pecking in adult birds is seen in cases of lack of bedding at an early age (28) or limiting its amount (38).

3.3.3 Influence of bird perches: Providing an adequate and timely access to perches is important for birds in connection to feather pecking and cannibalism $(40,47)$. The perches help with the development of the skeleton and muscles and also make movement easier (increase activity) for the birds and encourage their natural behavior (7). Perches also increase the amount of used vertical space and their presence ensures the possibility of escape from unwanted social engagements or unfortunate conditions of the environment (11, 32).

3.3.4 Influence of aerated breeze blocks: Enrichment of the environment through the placement of aerated breeze blocks lowers the 
NIKOLOV S., et al.

onset of injurious pecking in birds (9). It encourages the natural pecking of the ground and dulling of the beak which strongly influences damaging behavior $(28,36)$.

II. Intrinsic factors. Intrinsic factors are those that depend on the bird - factors of the organism that influence injurious pecking. Seven groups of biotic factors fall into the category: social, sex, age, stress, central nervous, hereditary, and immunological.

1. Behavioral/social factors: Behavioral characteristics of the individuals lead to a variety of interactions between birds in their social group which leads to damaging influence $(16,40)$.

\subsection{Social training (imitating behavior):}

Social training allows behavioral innovations to spread fast among the population and that way the adaptation towards different environments and unpredictable conditions is made easier (51). Birds can change their behavior through social transfer (imitating one another) while they watch other individuals from their species (12). At first injurious pecking is done by a small number of birds in the group but it is easily spread (17). It is confirmed that social training makes it easier and faster for onsets of feather pecking (19) and cannibalism in domestic and game birds to develop (52).

1.2 Sexual behavior: Pecking of female pheasants from male individuals during mating is a form of aggressive behavior (50). The act of mating during the day is influenced by the cycle of egg laying because mating decreases around the period of laying (53). Pheasants and quails usually lay their eggs in the afternoon (compared to domestic chickens which lay eggs in the morning) so the act of mating is in the morning and early evening (54). The speed of mating is increased in the evening (19 h) which is at the same period of time as the act of cannibalism from the male to the female he had mated with. Different models of aggressive behavior have been observed in the females during the day and their culmination is at the same time $(19 \mathrm{~h})$ and is connected to cannibalism $(50,53)$.

1.3 Stereotypical behavior: Stereotypical behavior is developed in unpredictable situations in which the individual doesn't have control over the environment and that leads to disappointment or dissatisfaction (55). Feather pecking has characteristics similar to obsessive-compulsive disorder in humans (trichotillomania) and mice (56). The level of stereotypical behavior is significantly higher in males compared to female pheasants. The higher percentage of stereotypical behavior in pheasants is monitored in the early hours (peaking at $12 \mathrm{~h}$ ) while in males the level of stereotypical behavior is mainly found at $13 \mathrm{~h}$ (50). Also even a minimal onset of stereotypical behavior leads to injurious pecking (49).

1.4 Influence of maternal behavior on the newly hatched: The conditions during which the eggs were hatched as well as the period of incubation and early history of life can have serious consequences on the behavioral development of young birds (40). It has been proven that chickens raised by a hatcher hen have lower mortality rates due to feather pecking and cannibalism (8). Chickens raised by a hatcher hen are less scared and have higher social motivation in adult age (40). Taking away the mothering care from young birds can have serious consequences: a higher onset of injurious pecking (8). It is interesting that birds that have undergone stress in young age have higher prevalence to develop feather pecking behavior in adult age (57).

2. Sex factors: Significant differences have been proven between the two sexes in relation to the prevalence for injurious pecking; male individuals are less likely to develop feather pecking behavior than females (12). It is determined that the presence of a cock in the herd of hens is a factor which lowers feather pecking (46). A higher onset of pecking and cannibalism between male pheasants has been observed $(3,50)$.

2.1 Sex hormones: Steroid hormones estrogens and androgens have a great impact on the behavior and injurious pecking in birds (1). The female sex hormones increase feather pecking and cannibalistic behavior in birds (12). A counter tendency of influence over feather pecking and cannibalism in birds is observed with male sex hormones although it decreases egg production (8). Low doses of testosterone lower injurious pecking but in high doses as well as in combination with estradiol they are significantly increased (12). It is proven that testosterone increases the aggressive and sexual behavior in domestic chickens (17).

2.2 The role of sex hormones on embryogenesis: The yolk of the egg contains significant amounts of steroid hormones such as estrogens and androgens (1) which can have a longstanding effect on the development of 
the brain and the behavior of the bird embryo (58). The collection of hormones in the yolk is a mechanism with which the mother can adapt the development of her offspring to the current conditions of the environment (8). The hormonally mediated effects of the mother are important for the development of injurious pecking in the offspring (1). The effect of testosterone in eggs speeds up the development of the chickens and makes them more aggressive and competitive than the others (59).

3. Age factor: The level of onset of feather pecking depends on the age of the birds (9, 38 ). In young age the lighter form of feather pecking dominates (48). It serves as learning behavior and is a form of social contact (28). The heavy forms of feather pecking and cannibalism develop in adult age which leads to worse feathering in birds in adult age (15, 29).

\section{Factors of fear and stress: Unfortunate} conditions can lead to stress in birds $(10,51)$. The high sensitivity towards stress comes from high levels of fear (9). The behavioral characteristics of lone individuals or different species of birds towards manifestations of fear and stress also play a role in the development of feather pecking and cannibalism (1) in turkeys (60) and ducks (61). Fear is the probability of the individual being easily scared (17). Birds who demonstrate higher levels of fear resort to feather pecking behavior (12). A connection between fear and injurious pecking of feathers has been determined (62). Feather pecking can increase the sense of fear and on the contrary fear can also be a precursor to feather pecking development (9). It is proven that different market lines of hens are different as far as fear levels, sensitivity to stress and aptitude to heavy feather pecking go (62).

- Hormone of stress (corticosterone): The influence of stress hormones and more specifically corticosterone is significant for the development of injurious pecking as well as feather pecking and cannibalism in birds (1). The increase of plasma concentration of corticosterone increases feather pecking and cannibalism in birds (63). It is determined that the levels of main corticosterone are higher in birds demonstrating more injurious pecking $(64,65)$. Adding corticosterone to the forage of growing birds leads to simulation of chronic stress and leads to lower growth rate, increase
NIKOLOV S., et al.

mental instability and increase in the levels of feather pecking in adult age (12).

5. Factors of the central nervous system: The nervous system regulates the behavior in birds directly and the neurohumoral regulates injurious pecking $(1,15)$. The behavioral characteristics connected to the strong susceptibility to damaging behavior and the influence of stress are determined by differences in neurophysiology and the birds' temperament (57), meaning the serotonin $(61$, $65,66)$, dopamine systems $(67,68)$ and noradrenaline $(8,12,64)$ which have causeeffect connection to the onset of feather pecking and cannibalism (69).

5.1 Influence of serotonin (5-HT): The serotonin activity plays a key role in the physiological characteristics of injurious pecking $(10,65)$. The division of serotonin fibers in the bird brain controls the influence of serotonin (5-HT) over fear and social behavior $(62,66,69)$. It is proven that 5-HT has an important role in the response to stress situations in chickens during manipulations or moving to an unknown environment $(11,68)$.

5.2 Influence of dopamine: Dopamine conduction of nervous impulses in the brain also has a key role in the neurophysiological characteristics of injurious pecking $(12,67)$. Dopamine improves the capability of coping with fear and stress and leads to lower feather pecking levels $(1,70)$. Bird individuals are different from each other as far as dopamine synthesis in the CNS goes. Those that manifest more feather pecking have lower plasma levels of dopamine in their blood $(64,65,68)$. Birds that manifest injurious pecking have less dopamine receptors or the receptors are blocked which leads to an increase in pleasure gained by feather pecking (11).

5.3 Influence of noradrenalin (NA): Catecholamines have an important role in some behavioral pathology in bird species (8, 12). It is determined that when birds manifesting injurious pecking are a subject of stress they respond with a higher plasma levels of NA (65) in comparison to those with lower levels of feather pecking which respond to stress with lower levels of NA (64).

6. Genetic/ hereditary factors: Differences in feather pecking levels, quality of the feathering and mortality from cannibalism between different populations are determined by the genetic fund of birds $(15,71)$. Feather pecking is inherited in the offspring as a "hereditary 
NIKOLOV S., et al.

factor" $(8,48)$. There is a significant difference between the genetic origin of the birds connected to the quality of feathering, skin lesions and cannibalism (16, 57). Molecular studies show that the genetic fund of feather pecking is poligenius (72) while cannibalism and aggression in a combination can be influenced by one or a few main genes $(73,74)$.

6.1 Genotypic manifestation (QTL-genome region): Feather pecking in certain breeds of egg laying hens $(48,74)$ is connected to genome regions (QTL) which are responsible for behavior (15). QTL regions are connected to complicated behavioral traits of feather pecking and cannibalism and the genes for fear and anxiety in birds (1). The suggestive locus QTL is identified in mild feather pecking cases in young individuals and in heavy feather pecking case in adults (73). The presence of these additive genetic effects is the base of feather pecking behavior determined through hereditary traits (71).

6.2 Phenotypic manifestation - the importance of pigmentation of the feathering: The condition of the feathering is connected to genome regions QTL identical with gene (PMEL17) for "white-dominant" color $(2,72)$. Pigmentation of the feathers as a hereditary sign has a significant influence on the risk of turning the bird into a victim because the pigmented individuals are more sensitive to injurious pecking than whites (8, 48). The higher frequency of feather pecking is examined from pigmented towards white birds which is due to the fact that there is a bigger contrast between the dark feathers and light skin $(12,74)$.

7. Immunological factors: A connection between immune reactivity and stress in birds with damaging behavior - feather pecking and cannibalism has been proven $(9,75)$. Phenotypic and genotypic onsets of heavy feather pecking have a connection to the immune system. Birds that manifest more injurious pecking have higher levels of specific humoral immunity $(75,76)$. There are significant differences between the populations of birds demonstrating injurious pecking and their physiological response to regulation from the adrenal glands and the immune system (63). The birds are exposed to endotoxins (different antigens) in the air, forage, water, feces and vaccines and their effect is different according to the dosage, time of exposure and overall condition of the individual (75). Birds that don't develop injurious pecking have quick and transient behavioral and physiological changes with less negative effects of weight gain, organ development and internal temperature when exposed to immunological stress-LPS immunological probe $(15,60)$. Birds with high levels of feather pecking have a more turbulent response to an immunological probe and a smaller number of white blood cells after vaccination $(43,76)$.

\section{CONCLUSION}

Unbalanced and deficit feeding especially in terms of aromaaminoacids (TRP, PHE, TYR) and non-starch polysaccharides (NSP) in the ration have a significant impact in the etiology of injurious pecking. The abiotic factors (light, temperature, sound and air) have a role in damaging behavior, the unfortunate factors of the environment cause stressful situations in birds and as a coping mechanism they develop injurious pecking. The conditions of breeding, the spatial parameters and the enrichment of the environment are very important for the birds because they give the opportunity for close contact and a variety of interactions between them which includes damaging behavior. The behavioral characteristics of individuals lead to different relationships between birds in their social group which lead to poor social motivation and dissatisfaction which onsets injurious pecking. On the other hand heredity, the individuality of the type of nervous system - transmissions of impulses in the brain (5-HT, DA, NA), the immune reactivity and stress (corticosterone) regulate injurious pecking in individual birds. The connection between extrinsic and intrinsic factors is significant and they can't be interpreted on their own and independently from one another.

\section{REFERENCES}

1. Rodenburg, T.B., M.M. van Krimpen, I.C. de Jong, E.N. de Haas, M.S. Kops, B.J. Riedstra, R.E. Nordquist, J.P. Wagenaar, M. Bestman and C.J. Nicol, The prevention and control of feather pecking in laying hens: identifying the underlying principles. Worlds Poultry Science Journal: 69, 361373, 2013.

2. Jensen, P., Genetics and genomics of animal welfare. In: Mench, J.A. (Ed.), Advances in Agricultural Animal Welfare. Science and Practice, Elsevier, Oxford. pp. 25-48, 2018. 
3. Draycott, R.A.H., K. Pock and J.P. Carroll, Sustainable management of a wild pheasant population in Austria. Zeitschrift für Jagdwissenschaft, 48: 346-353, 2002.

4. Draycott, R.A.H., M.I.A. Woodburn, J.P. Carroll and R.B., Sage, Effects of spring supplementary feeding on population density and breeding success of released pheasants Phasianus colchicus in Britain. Wildl Biol, 11: 177-182, 2005.

5. Kuzniacka, J. and M. Adamski, Growth rate of body weight and measurements in pheasants reared up to the 24th week of life. Arch Tierz, 53, 360-367, 2010.

6. Kokoszynski, D., Z. Bernacki and A. Cisowska, Growth and development of young game pheasants (Phasianus colchicus). Arch Tierz, 54, 83-92, 2011.

7. Hrabcakova, P., I. Bedanova, E. Voslarova, V. Pistekova and V. Vecerek, Evaluation of tonic immobility in common pheasant hens kept in different housing systems during laying period. Archiv fur Tierzucht, 55 (6), 626-632, 2012.

8. Rodenburg, T.B., J. Komen, E.D. Ellen, K.A. Uitdehaag, J.A.M. Van Arendonk, Selection method and early-life history affect behavioural development, feather pecking and cannibalism in laying hens: a review. Applied Animal Behaviour Science, 110 (3-4), 217-28, 2008.

9. de Haas, E.N., J.E., Bolhuis, I.C., de Jong, B., Kemp, A.M., Janczac and T.B., Rodenburg, Predicting feather damage in laying hens during the laying period. Is it the past or is it the present? Applied Animal Behaviour Science, 160, 75-85, 2014.

10.Birkl, P., L. Frankeb, T. Bas Rodenburgc, E. Ellend and A. Harlander-Matauscheka, A role for plasma aromatic amino acids in injurious pecking behavior in laying hens. Physiology \& Behavior, 175, 88-96, 2017.

11.Daigle, C.L., Chapter 11 - Controlling Feather Pecking and Cannibalism in Egg Laying Flocks. In: Patricia Hester (ed.) Egg Innovations and Strategies for Improvements. London, UK: Academic Press., 111-121, 2017.

12.Sedlackova, M., B. Bilcik and L. Kostal, Feather pecking in laying hens: Environmental and endogenous factors. Acta Veterinaria Brno, 73, 521-531, 2004.

13.Lambton, S.L., T.G. Knowles, C. Yorke and C.J. Nicol, The risk factors affecting the development of vent pecking and cannibalism in free-range and organic
NIKOLOV S., et al. laying hens. Animal Welfare, 24, 101-111, 2015.

14. Van Krimpen, M.M., R.P. Kwakkel, C.M.C. van der Peet-Schwering, L.A. den Hartog and M.W.A. Verstegen, Effects of nutrient dilution andnonstarch polysaccharide concentration in rearing and laying dietson eating behavior and feather damage of rearing and laying hens. Poultry Science Journal, 88, 759-773, 2009.

15.Parmentier, H.K., T.B. Rodenburg, G.D. Reilingh, B. Beerda B. and Kemp, Does enhancement of specific immune responses predispose laying hens for feather pecking? Poultry Science Journal, 88, 536-542, 2009.

16.Gilani, A-M., T.G. Knowles and C.J. Nicol, The effect of rearing environment on feather pecking in young and adult laying hens. Applied Animal Behaviour Science, 148, 54-63, 2013.

17.Van Krimpen, M.M., R.P. Kwakkel, B.F.J. Reuvekamp, C.M.C. Van Der PeetSchwering, L.A. Den Hartog and M.W.A. Verstegen, Impact of feeding management on feather pecking in laying hens. Worlds Poultry Science Journal, 61, 663-685, 2005.

18.Elwinger, K., R. Tauson, M. Tufvesson and C. Hartmann, Feeding of layers kept in an organic feed environment. In 11th. European Poultry Conference, Bremen, 610, 2002.

19.McAdie, T.M. and L.J. Keeling, The social transmission of feather pecking in laying hens: effects of environment and age. Applied Animal Behaviour Science, 75, 147-159, 2002.

20.Bozakova N. A., Girginov, D. G., Atanasov, A. P., Welfare of Barred Plymouth Rock poultry flocks supplemented with zinc, vitamin C and Larginine during the hot summer period using a mathematical assessment model. Proceeding of the 16-th ISAH Congress, Nanjing, China, 23-26, 2013.

21.Sirén, M.J., Cannibalism in cockerels and pheasants. Acta Veterinaria Scandinavica 4, Supp. 1, 1-47, 1963.

22.Madsen, H., On feather picking and cannibalism in pheasant and partridge chicks, particularly in relation to the amino acid arginine. Acta Veterinaria Scandinavica, 7, 272-287, 1966.

23.McKeegan, D.E.F., Savory, C.J., Macleod, M.G. and Mitchell, M.A., Development of pecking damage in layer pullets in relation 
to dietary protein source. British Poultry Science 42 (1): 33-42, 2001.

24.Bozakova N., Effect of vitamin $\mathrm{C}$ and zinc on ethological and oxidative performance in laying hens during a cold period. Journal of Hygienic Engineering and Design, 30, 115119, 2020.

25.Bozakova N., L. Sotirov, K. Nedelkov and M. Simeonov, Welfare improvement of laying hens under semi-open rearing during cold period with $\mathrm{Zn}$ and vitamin $\mathrm{C}$ supplementation. Proceedings of the XVII International Congress on Animal Hygiene, Košice, Slovakia, 35-37, 2015.

26.Latshaw J.D., T.Y. Morishita, C.F. Sarver and J. Thilsted, Selenium Toxicity in Breeding Ring-Necked Pheasants (Phasianus colchicus). Avian Diseases, 48, 935-939, 2004.

27. Yngvesson, J., L.J. Keeling and R.C. Newberry, Individual production differences do not explain cannibalistic behaviour in laying hens. British Poultry Science, 45, 453-462, 2004.

28.Lambton, S.L., C.J. Nicol, M. Friel, D.C.J. Main, J.L. McKinstry, C.M. Sherwin, J. Walton and C.A. Weeks, A bespoke management package can reduce the levels of injurious pecking in loose housed laying hen flocks. Veterinary Record, 172, 423430, 2013.

29.Harlander-Matauschek, A. and K. Häusler, Understanding feather eating behaviour in laying hens. Applied Animal Behaviour Science, 117, 35-41, 2009.

30.Kjaer J.B., Effects of stocking density and group size on the condition of the skin and feathers of pheasant chicks. Veterinary Record, 154, 556-558, 2004.

31.Steenfeldt S., J.B. Kjaer and R.M. Engberg, Effect of feeding silages or carrots as supplements to laying hens on production performance, nutrient digestibility, gut structure, gut microflora and feather pecking behaviour. British Poultry Science, 48, 454-468, 2007.

32.Lambton, S.L., T.G. Knowles, C. Yorke and C.J. Nicol, The risk factors affecting the development of gentle and severe feather pecking in loose housed laying hens. Applied Animal Behaviour Science, 123, 32-42, 2010.

33.Nicol, C.J., C. Pötszch, K. Lewis and L.E. Green, Matched concurrent case control study of risk factors for feather pecking in hens on free-range commercial farms in the
NIKOLOV S., et al.

UK. British Poultry Science, 44, 515-523, 2003.

34.Pötzsch, C.J., K. Lewis, C.J. Nicol and L.E Green, A cross-sectional study of the prevalence of vent pecking in laying hens in alternative systems and its associations with feather pecking, management and disease. Applied Animal Behaviour Science, 74, 259-272, 2001.

35.Drake, K.A., C.A. Donnelly and M.S. Dawkins, Influence of rearing and lay risk factors on propensity for feather damage in laying hens. British Poultry Science, 51, 725-733, 2010.

36.Nicol, C.J., M. Bestman, A.M. Gilani, E.N. de Haas, I.C. de Jong, S.L. Lambton, J.P. Wagenaar, C.A. Weeks and T.B. Rodenburg, The prevention and control of feather pecking: application to commercial systems. World's Poultry Science Journal, 69, 775-788, 2013.

37.Gilani, A-M., Investigation of rearing environment and its association with feather pecking in free range pullets. $P h D$ Thesis, University of Bristol, UK, 2012.

38.Bestman, M., P. Koene and J.P. Wagenaar, Influence of farm factors on the occurrence of feather pecking in organic reared hens and their predictability for feather pecking in the laying period. Applied Animal Behaviour Science, 121, 120-125, 2009.

39. Yngvesson, J., J. Gustafson, C. Berg, I. Larsson, S. Gunnarsson and K. Oden, A field study of access to day light, ammonia, plumage condition and mortality in loose housed laying hens in south east Sweden. Proceedings of the 30th Poultry Science Symposium - Alternative systems for Poultry: health welfare and productivity, Glasgow, pp. 53, 2011.

40.Riber, A.B., B.L. Nielsen, C. Ritz, and B. Forkman, Diurnal activity and synchrony in layer hen chicks (Gallus gallus domesticus). Applied Animal Behaviour Science, 108, 276-287, 2007.

41.Bright, A., Plumage colour and feather pecking in laying hens, a chicken perspective? Br. Poult. Sci. 48, 253-263, 2007.

42.Markarian, M., Diseases of birds and avian embryos, 183-185, 1998 (BG).

43.Zimmerman, P.H., A.C. Lindberg, S.J. Pope, E. Glen, J.E. Bolhuis and C.J. Nicol, The effect of stocking density, flock size and modified manage-ment on laying hen behaviour and welfare in a non-cage 
system. Applied Animal Behaviour Science, 101, 111-124, 2006.

44.Leone, E.H., M.C. Christman, L. Douglass and I. Estevez, Separating the impact of group size, density, and enclosure size on broiler movement and space use at a decreasing perimeter to area ratio. Behavioural Processes, 83, 16-22, 2010.

45.Lay, D.C., R.M. Fulton, P.Y. Hester, D.M. Karcher, J.B. Kjaer, J.A. Mench, B.A. Mullens, R.C. Newberry, C.J. Nicol, N.P. O'Sullivan and R.E. Porter, Hen welfare in different housing systems. Poultry Science Journal, 90, 278-294, 2011.

46.Bestman, M.W.P. and J.P. Wagenaar, Farm level factors associated with feather pecking in organic laying hens. Livestock Production Science, 80, 133-140, 2003.

47.Pohle, K. and H.W. Cheng, Comparative effects of furnished and battery cages on egg production and physiological parameters in White Leghorn hens. Poultry Science Journal, 88, 2042-2051, 2009.

48.Kjaer, J.B. and P. Sörensen, Feather pecking and cannibalism in free-range laying hens as affected by genotype, dietary level of methionine + cystine, light intensity during rearing and age at first access to the range area. Applied Animal Behaviour Science, 76, 21-39, 2002.

49.Glatz, P.C. and M. Bourke, Chapter 1. Pecking problems, in: Beak trimming handbook for egg producers: best practices for minimising cannibalism in poultry, $\mathrm{pp}$. 1-5, 2006 (Collingwood Victoria, Australia, CSIRO Publishing).

50.Zapletal, D., P. Suchy, E. Strakova, F. Vitula and J. Kuchtik, Behaviour patterns of the cagehoused breeding flock of pheasants (Phasianus colchicus). Acta Universitatis Agriculturae Et Silviculturae Mendelianae Brunensis, 3, 215-220, 2011.

51.Campo, J.L. and M.T. Prieto, Effects of moist litter, perches, and droppings pit on fluctuating asymmetry, tonic immobility duration, and heterophil-to-lymphocyte ratio of laying hens. Poultry Science Journal, 88, 708-713, 2009.

52.Zeltner, E., T. Klein, and B. Huber-Eicher, Is there social transmission of feather pecking in groups of laying hen chicks? Animal Behaviour Science, 60, 211-216, 2000.

53.Appleby, M.C., J.A. Mench and B.O. Hughes, Poultry behaviour and welfare. Wallingford: CABI, 276, p. ISBN 0-85199667-1, 2004.
NIKOLOV S., et al.

54.Ottinger, M.A., W.M. Schleidt and E. Russek, Daily pattern of courtship and mating behavior in the male Japanese quail. Behavioural Processes, 7, 223-233, 1982.

55.Tanaka, T. and J.F. Hurnik, Comparison of behavior and performance of laying hens housed in battery cages and an aviary. Poultry Science Journal, 71, 235-243, 1992.

56. Van Zeeland, Y.R.A., B.M. Spruit, T.B. Rodenburg, B. Riedstra, Y.M. Van Hierden, B. Buitenhuis, S.M. Korte and J.T. Lumeij, Feather damaging behaviour in parrots: A review with consideration of comparative aspects. Applied Animal Behaviour Science, 121, 75-95, 2009.

57.Rodenburg, T.B., A.J. Buitenhuis, B. Ask, K.A. Uitdehaag, P. Koene, J.J. van der Poel, J.A.M. van Arendonk and $\mathrm{H}$. Bovenhuis, Genetic and phenotypic correlations between feather pecking and open-field response in laying hens at two different ages. Behavior Genetics, 34, 407415, 2004.

58. Von Engelhardt, N. and T.G.G. Groothuis, Maternal hormones in avian eggs, in: D.O. Norris, \& K.H. Lopez, (Eds) Hormones and Reproduction of Vertebrates, Birds, 4, 91127, 2011.

59.Eising, C.M., W. Muller and T.G.G. Groothuis, Avian mothers create different phenotypes by hormone deposition in their eggs. Biology Letters, 2, 20-22, 2006.

60.Erasmus, M.A., Individual and genetic differences in fearfulness: effects on feather pecking and meat quality of turkeys [dissertation]. Michigan State University; East Lansing, Michigan, United States, 2014.

61.Rodenburg T.B., M.B.M. Bracke, J. Berk, J. Cooper, J.M. Faure, D. Guémené, G. Guy, A. Harlander, T. Jones, U. Knierim, K. Kuhnt, H. Pingel, K. Reiter, J. Serviére and M.A.W. Ruis, Welfare of ducks in European duck husbandry systems. World's Poultry Science Journal, 61, 633-646, 2005.

62.Uitdehaag, K.A., T.B. Rodenburg, C.G. Van Reenen, R.E. Koopmanschap, G.D. Reilingh, B. Engel, W.G. Buist, H. Komen and J.E. Bolhuis, Effects of genetic background and social environment on behavioralresponse to manual restraint and monoamine functioning in layinghens. Poultry Science Journal, 90, 1629-1636, 2011. 
63.Cheng, H. and W.M. Muir, The effects of genetic selection for survivability and productivity on chicken physiological homeostasis. World's Poultry Science Journal, 61, 383-397, 2005.

64.Cheng, H.W., G. Dillworth, P. Singleton, Y. Chen and W.M. Muir, Effects of group selection for productivity and longevity on blood concentrations of serotonin, catecholamines, and corticosterone of laying hens. Poultry Science Journal, 80, 1278-1285, 2001.

65.Van Hierden, Y.M., S.M. Korte, E.W. Ruesink, C.G. Van Reenen, B. Engel, G.A.H. Korte-Bouws, J.M. Koolhaas and H.J. Blokhuis, Adrenocortical reactivity and central serotonin and dopamine turnover in young chicks from a high and low featherpecking line of laying hens. Physiology \& Behavior, 75, 653-659, 2002b.

66.Kops, M.S., J.B. Kjaer, O. Gunturkun, K.G.C. Westphal, G.A.H. Korte-Bouws, B. Olivier, J.E. Bolhuis and S.M. Korte, Serotonin release in the caudal nidopallium of adult laying hens genetically selected for high and low feather pecking behavior: an in vivo microdialysis study. Behavioural Brain Research, 268, 81-87, 2014.

67.Van Hierden, Y.M., J.M. Koolhaas, L.U. Kost'al, P. Vyboh, M. Sedlackova, M. Rajman, M. Jurani and S.M. Korte, Chicks from a high and low feather pecking line of laying hens differ in apomorphine sensitivity. Physiology \& Behavior, 84, 471-477, 2005.

68.Kops, M.S., E.N. de Haas, T.B. Rodenburg, E.D. Ellen, G.A.H. Korte-Bouws, B. Olivier, O. Gunturkun, J.E. Bolhuis and S.M. Korte, Effects of feather pecking phenotype (sever feather peckers, victims and non-peckers) on serotonergic and dopaminergic activity in four brain areas of laying hens (Gallus gallus domesticus). Physiology \& Behavior, 120, 77-82, 2013.

69.Bolhuis, J.E., E.D. Ellen, C.G. Van Reenen, J. De Groot, J. Ten Napel, R. Koopmanschap, G. De Vries Reilingh, K.A. Uitdehaag, B. Kemp and T.B. Rodenburg,
NIKOLOV S., et al.

Effects of genetic group selection against mortality on behaviour and peripheral serotonin in domestic laying hens with trimmed and intact beaks. Physiology \& Behavior, 97, 470-475, 2009.

70.Kjaer, J.B. and Hocking, P., Genetic influences on feather pecking and cannibalism. In G.C. Perry (ed.), Welfare of the Laying hen. CABI Publishing, Wallingford, UK, 27, 109-121, 2004.

71.Newberry, R.C., L. Keeling, I. Estevez and B. Bilcik, Behaviour when young as a predictor of severe feather pecking in adult laying hens: the redirected foraging hypothesis revisited. Applied Animal Behaviour Science, 107, 262-274, 2007.

72.Karlsson, A.C., S. Kerje, L. Andersson and P. Jensen, Genotype at the PMEL17 locus affects social and explorative behaviour in chickens. British Poultry Science, 51, 170177, 2010.

73.Buitenhuis, A.J., T.B. Rodenburg, Y.M. Van Hierden, M. Siwek, S.J.B. Cornelissen, M.G.B. Nieuwland, R.P.M. Crooijmans, M.A.M. Groenen, P. Koene, S.M. Korte, H. Bovenhuis and J.J. Van der Poel, Mapping Quantitative Trait Loci affecting feather pecking behaviour and stress responses in laying hens. Poultry Science Journal, 82, 1215-1222, 2003.

74.Kjaer, J.B. and H. Jorgensen, Heart rate variability in domestic chicken lines genetically selected on feather pecking behavior. Genes Brain and Behavior, 10, 747-755, 2011.

75.Wideman, R.F., M.E. Chapman, W. Wang, and G.F. Erf, Immune modulation of the pulmonary hypertensive response to bacterial lipopolysaccharide (endotoxin) in broilers. Poultry Science Journal, 83, 624637, 2004.

76.Buitenhuis, A.J., J.B. Kjaer, R. Labouriau and H.R. Juul-Madsen, Altered circulating levels of serotonin and immunological changes in laying hens divergently selected for feather pecking behavior. Poultry Science Journal, 85, 1722-1728, 2006. 